\title{
Child pedestrian and bicyclist injuries: results of community surveillance and a case-control study
}

Jess F Kraus, Elizabeth Gerken Hooten, Kathryn A Brown, Corinne Peek-Asa, Constance Heye, David L McArthur

\begin{abstract}
Objectives-To describe the dimensions of childhood pedestrian and bicyclist injuries in Long Beach, California, and to identify risk factors for these injuries.
\end{abstract}

Population-Long Beach residents aged 0-14 years who were involved in an auto versus pedestrian or bicyclist incident that resulted in a hospital visit and/or police response, between 1 September 1988 and 31 August 1990.

Methods-Cases were identified retrospectively using hospital charts, police records, and coroner's reports; demographic, clinical, and situational information were abstracted from the same. A nested case-control study was conducted to examine the street environments where children were injured, and to identify environmental risk factors at these case sites.

Results-288 children comprised the sample population. Midblock dart-outs emerged as the single most common type of incident. Most incidents happened on residential streets, but the risk of injury was greatest on larger boulevards, and tended to cluster by region within the city. Adjusted odds ratios show that case sites had a larger proportion of traffic exceeding posted speed limits, and were also four times more likely to be near a convenience store, gas station, or fast food store than control sites.

Conclusions-The findings of this study suggest three possible routes for the prevention of childhood pedestrian and bicyclist injuries: education, law enforcement, and environmental modification.

(Injury Prevention 1996; 2: 212-218)

Keywords: pedestrian, bicyclist, epidemiology, risk factors.

Among children, pedestrian injuries rank as a leading cause of death in the US, and constitute a growing concern in many urban settings worldwide. ${ }^{1}$ In 1993,818 pedestrians in the US aged 15 or younger died after being struck by a motor vehicle, representing $25 \%$ of all motor vehicle related fatalities in that age group, and an additional estimated 31000 children were injured as pedestrians. ${ }^{2} \mathrm{~A}$ study of child pedestrian injuries in Memphis, Tennessee, found the normative injured child to be a male of elementary school age, injured while crossing the street, and living in a high density urban area. Most injuries occur after school hours on local roads. Known risk markers for pedestrian injuries include poverty, ${ }^{3-6}$ living in a multifamily dwelling, ${ }^{7}$ living in an area with busy streets (relatively high posted speeds and/or greater traffic volumes), ${ }^{78}$ male gender, and non-white ethnicity. ${ }^{369}$ In 1993,310 child bicyclists were killed in the US, and an additional 30000 were injured. ${ }^{2}$ Thirty six per cent of all bicycle related deaths occur in the 5-15 year age group, with the highest rates of fatal injuries among males age $9-10$ years. ${ }^{10}$ While most bicycle related injuries are not fatal, many lead to head injuries that can have serious medical consequences. ${ }^{10}$ There has been a recent trend in many areas of the US to adopt child bicycle helmet laws, and helmets are also being considered as an injury prevention strategy for pedestrians in Japan.

This study was undertaken in response to concern initially expressed in 1990 by the medical community of Long Beach, California that pediatric pedestrian and bicyclist injuries were increasing in number and might be overrepresented among certain ethnic groups. Thus, the purpose of the investigation was to determine the magnitude of childhood pedestrian and bicyclist injuries in Long Beach and to identify risk factors for these injuries. The broader aim of the study was to provide information and prevention recommendations to the City of Long Beach toward the goal of reducing these injuries.

\section{Methods}

Long Beach is located within Los Angeles County, California with a 1990 population of 429433 residents, of which 96648 were children under the age 15 . The study sample consisted of 288 Long Beach residents 0-14 years of age who were involved in an auto versus pedestrian or auto versus bicyclist incident between 1 September 1988 and 31 August 1990. Cases were identified by a complete retrospective review of all such incidents during this period recorded in either police reports or medical records in each of the four hospitals which serve Long Beach: two level I trauma centers and two non-trauma hospitals. (Both of the trauma centers and one of the non-trauma hospitals are located in the city of Long Beach; the fourth hospital lies just outside the boundary of Long Beach.) Los Angeles County coroner's records were used to supplement information gathered on the 15 fatal cases.

Medical record abstraction provided demographic information including age, gender, 
ethnicity, and local address. Clinical information included assessment of prehospital and emergency department treatments, diagnoses, severity of injuries, inpatient treatment, and total hospital costs. Police reports yielded information on injury location site, detailed description of the event, party at fault, vehicle code violations, witnesses' statements, and other related details. For the 15 fatal cases, the cause and manner of death were confirmed with coroner's records. Abbreviated injury scale $(A I S)^{11}$ scores were calculated from ICD9 diagnosis codes assigned in the hospital. These scores assign a seven digit numeric code which specifies body region, exact type of injury, and expected severity of that injury on an integer scale of 1 (minimal) to 6 (unsurvivable).

Because many potential environmental risk factors are not recorded in routine police reports, a case site/control site investigation was undertaken. Environmental assessments were conducted for 111 injury case sites and 111 non-injury control sites addressing a variety of issues at and around the general location of the incident. Similar case-site/control-site designs have recently been used by Stevenson et $a l,{ }^{12}$ and Agran et al. ${ }^{13}$ Case sites were selected from the sample of injured pedestrians to achieve geographic representation for the entire city, in an attempt to distribute this effort over as many environmental variations as could be found within the study's boundaries. Sites with multiple injury occurrences were examined only once, while sites within a half city block of a previously selected site were not examined separately. Control sites were randomly selected within two blocks of the case location: reference to a predetermined compass rose determined the direction and number of blocks (one or two) in which the field investigator was to move to identify the control site. 'Midblock' events were defined as those occurring between two defined intersections. Environmental measurements included street width, traffic speed, signage, existence and condition of crosswalk, traffic signal placement, and visual obstructions. Traffic speed was determined by averaging 10 speed readings taken with a radar gun at each site. Environmental assessments for $95 \%$ of the case and control sites were made at approximately the same time of day as the original injury; weekday incidents were assessed on weekdays while weekend incidents were assessed on weekends only.

Injury and death rates were calculated using 1990 US census population estimates for the city of Long Beach. Race-ethnic categories used in the US census are 'white', 'black', 'Hispanic' and 'Asian'. Roadway mileage by type of roadway was estimated using a scaled official city map. Odds ratios to estimate the level of effect of purported risk factors were calculated using SAS. ${ }^{14}$

\section{Results}

For the two year period, 355 children were identified with injuries resulting from motor vehicle versus pedestrian or motor vehicle versus bicyclist collisions. Of those, 288 (15 of which were fatal) were Long Beach residents with injuries that occurred within the city boundaries: these children are referred to as 'incident cases'. Average age of pedestrian cases was 6.9 (range $0 \cdot 1-14 \cdot 1$ years), and of bicycle cases was $10 \cdot 2$ (range 3.0-14.9). The average annual incidence rate for both pedestrian and bicyclists combined was 154/100 000 children/year. The pedestrian injury rate was $117 / 100000 / y e a r$, and the bicyclist injury rate was 37/100 000/year. For each type of injury, however, the rate varied greatly according to the age and gender of the child. Children aged 5-9 years had the highest rates for pedestrian collisions, while children aged 10-14 years had the highest rates for bicycle collisions (figure). The average age of pedestrians hit on private property was 2.7 years, while the average age of children hit on public roadways was 6.5 years. As shown in table 1, injury rates for both types of collisions were consistently higher among males: boys had rates 2.3 times higher than those of girls.

Differences were also found among ethnic specific injury rates for both pedestrians and bicyclists. Pedestrian injury rates for blacks, Asians, and Hispanics were each nearly three times the rate for whites (table 1). Bicyclist injury rates reveal a different ethnic pattern: they were much lower than pedestrian rates, and while Asians had the highest rate of pedestrian injuries, they had the lowest rate of bicyclist injuries. Black children, followed by white and Hispanic children, had the highest bicyclist injury rates.

During the two year study period, 15 children died from their injuries, yielding an average annual fatality rate of $8 / 100000 /$ year. The case fatality rate for all injuries was $5 / 100$ hospital treated incidents; among pedestrians the rate was $6 / 100$, and among bicyclists it was $3 / 100$.

\section{INCIDENT LOCATION}

When collisions were plotted on a map of Long Beach, incident locations were found to cluster in one area of the city. Nearly half of all collisions occurred within this fairly well defined geographic area, which covers approximately $9 \cdot 1$ square miles. This area is characterized by numerous apartment buildings, narrow streets, numerous parked cars, a paucity of

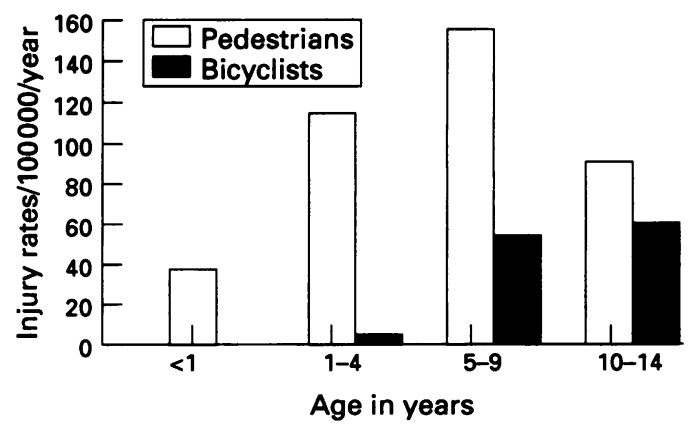

Pedestrian and bicyclist injury rates/100 000/year by age and mechanism, Long Beach, CA, 1988-90. 
Table 1 Child pedestrian and bicyclist-motor vehicle injury rates by gender and race, Long Beach, $C A, 1988-90$

\begin{tabular}{|c|c|c|c|c|c|c|}
\hline \multirow[b]{2}{*}{ Category } & \multicolumn{2}{|c|}{ Pedestrian } & \multicolumn{2}{|l|}{ Bicyclist } & \multicolumn{2}{|l|}{ Total } \\
\hline & No $(\%)$ & Rate $^{\star}$ & No $(\%)$ & Rate ${ }^{\star}$ & No $(\%)$ & Rate $^{\star}$ \\
\hline \multicolumn{7}{|l|}{ Gender } \\
\hline Male & $149(68)$ & 156 & $53(77)$ & 56 & $202(70)$ & 212 \\
\hline Female & $70(32)$ & 76 & $16(23)$ & 17 & $86(30)$ & 94 \\
\hline \multicolumn{7}{|l|}{ Race } \\
\hline White & $35(16)$ & 55 & $22(35)$ & 35 & $57(20)$ & 90 \\
\hline Hispanic & $86(40)$ & 141 & $20(32)$ & 33 & $106(38)$ & 173 \\
\hline Asian & $51(24)$ & 158 & $6(10)$ & 19 & $57(20)$ & 177 \\
\hline Black & $43(20)$ & 141 & $14(22)$ & 46 & $57(20)$ & 187 \\
\hline Fatalities & $13(6)$ & 7 & $2(3)$ & 1 & $15(5)$ & 8 \\
\hline Total & $219(76)$ & 117 & 69 (24) & 37 & $288(100)$ & 154 \\
\hline
\end{tabular}

*Average annual rate per 100000 residents 0-14 years of Long Beach.

officially designated play areas, and relatively few non-official or opportunistic play areas, for example, a very dense urban environment. The areas with lower rates of injury were characterized by residential homes, wide streets, a larger number of parks and play areas, and a general atmosphere of orderliness. Table 2 shows the distribution of injury events by geographic location.

Road type information was available for $92 \%$ of records for collisions that occurred on a public roadway. The most common road type was the residential street, accounting for $52 \%$ of pedestrian collisions and $63 \%$ of bike collisions. Residential streets comprise $70 \%$ of the non-freeway roads in Long Beach; hence, they are under-represented among injury-causing crash events. While residential roads are the single most common crash site, they do not pose the greatest risk to pediatric pedestrians and bicyclists.

Only six (3\%) of pedestrian collisions occurred in non-traffic situations - four in driveways and two in parking lots. Two (3\%) of bicyclist injuries also occurred in parking lots. Fourteen per cent of all injuries (pedestrian and bicycle combined) happened directly in front of the child's residence. More than half were within $3 / 10$ ths of a mile from the child's home, and $64 \%$ were within the same census tract as residence. Census tracts in Long Beach cover, on average, 39 block groups and range in size from $0.6 \mathrm{~km}^{2}$ to $3.5 \mathrm{~km}^{2}$, with an average area of $2.5 \mathrm{~km}^{2}$.

TIME

Over half of the injuries occurred between $3 \mathrm{pm}$ and $9 \mathrm{pm}$. Fewer than $14 \%$ occurred before noon, and only $4 \%$ after $9 \mathrm{pm}$. Injuries were equally likely to occur on any given day of

Table 2 Child pedestrian and bicyclist-motor vehicle injuries by geographic region, Long Beach, CA, 1988-90

\begin{tabular}{lccccc}
\hline & $\begin{array}{l}\text { No of } \\
\text { pedestrian } \\
\text { injuries }\end{array}$ & $\begin{array}{l}\text { No of } \\
\text { bicyclist } \\
\text { injuries }\end{array}$ & $\begin{array}{l}\text { Area in } \\
\text { square } \\
\text { miles }\end{array}$ & $\begin{array}{l}\text { Population/ } \\
\text { square } \\
\text { mile }\end{array}$ & $\begin{array}{l}\text { Rate/ } \\
100000 \\
\text { children }\end{array}$ \\
\hline (A) Apartments, small homes & 24 & 10 & $10 \cdot 8$ & 8439 & $146 \cdot 2$ \\
(B) Commercial apartments & 34 & 13 & $6 \cdot 6$ & 11980 & $214 \cdot 6$ \\
(C) Dense, older urban area & 110 & 21 & $9 \cdot 1$ & 10185 & $521 \cdot 7$ \\
(D) Apartments, condominiums & 25 & 8 & $5 \cdot 6$ & 14178 & $270 \cdot 2$ \\
(E) Larger single family homes & 8 & 11 & $20 \cdot 0$ & 4427 & $134 \cdot 0$ \\
\hline
\end{tabular}

the week. Monthly and seasonal variations were apparent, though monthly differences were not statistically significant. The four month period from April to July included almost one half of the incidents, while the four month period from November to March (Southern California's rainy season) included only one quarter.

\section{PEDESTRIAN/DRIVER ACTION}

According to police reports, $69 \%$ of pedestrian injuries occurred midblock, when the child darted into the street ('midblock dart-outs'); in more than half of these cases, the child is said to have run out from between parked cars (table 3). Similarly, $40 \%$ of bicycle collisions happened midblock, when children rode their bikes off the curb into traffic. Sixteen per cent of pedestrian incidents took place in a marked crosswalk, and $28 \%$ of bicycle incidents occurred at an intersection.

Among those cases reported to the City of Long Beach Police Department $(n=203)$, the investigating police officer determined that the child was at least partly at fault in $67 \%$ of all cases. Table 4 lists the most common vehicle code violations recorded for both children and drivers. There were few speeding violations and none related to motorists failing to obey stop signs, signals, etc. Thirty five or $13 \%$ of injury events were 'hit and run' collisions, all but three of which took place within the well defined high incidence region. Of the 15 fatalities, all but two were also found in this region, including all four of the hit and run fatalities.

\section{ENVIRONMENTAL FACTORS}

Crude odd ratios show that environmental characteristics of impact sites differed from comparison (non-injury) sites with respect to signage, street width, vehicular speed, and features of the neighbourhood. Among intersection sites with signage, injury sites were more likely to have traffic signals but were less likely to have traffic signs (table 5). Case sites were 3.4 times more likely to have a crosswalk at the intersection than control sites. This difference probably reflects exposure differences; that is, pedestrians are more likely to cross at crosswalks. Although injury sites were more likely to have posted speed limits,

Table 3 Number ( $\%$ ) of pedestrian and bicycle - motor vehicle collision injuries by child's action before collision, Long Beach, $C A, 1988-90$

\begin{tabular}{lc}
\hline Child's action & No $(\%)$ \\
\hline Pedestrians & $139(69)$ \\
Midblock dart-out & $32(16)$ \\
At marked crosswalk & $12(6)$ \\
On road/shoulder & $10(5)$ \\
At intersection, no crosswalk & $10(5)$ \\
In parking lot/driveway & $21(40)$ \\
Bicyclists & $15(28)$ \\
Off curb midblock & $7(13)$ \\
At intersection & $6(11)$ \\
Riding wrong way & $4(8)$ \\
Turning & \\
Carrying a passenger & \\
\hline
\end{tabular}


Table 4 Number (\%) of child pedestrian and bicycle-motor vehicle collision injuries by vehicle code violations, Long Beach, CA 1988-90

\begin{tabular}{|c|c|c|}
\hline $\begin{array}{l}\text { Violation } \\
\text { vehicle code }\end{array}$ & Description & $N o^{\star}(\%)$ \\
\hline $\begin{array}{l}\text { Violation involving pe } \\
21954 \\
21453 \\
21804\end{array}$ & $\begin{array}{l}\text { destrian/bicyclist } \\
\text { Pedestrian outside crosswalk } \\
\text { Pedestrian crossing against red light } \\
\text { Hazardous yield to approaching }\end{array}$ & $\begin{array}{l}63(22) \\
12(4) \\
8(3)\end{array}$ \\
\hline $\begin{array}{l}\text { Violation involving dri } \\
20001,20002 \\
22350\end{array}$ & $\begin{array}{l}\text { iver } \\
\text { Hit-and-run } \\
\text { Unsafe speed }\end{array}$ & $\begin{array}{l}28+(10) \\
10(4)\end{array}$ \\
\hline $\begin{array}{l}\text { Violation non-specific } \\
21950\end{array}$ & Pedestrian or driver at fault in crosswalk & $25(9)$ \\
\hline
\end{tabular}

«Some incident events may have had more than one violation.

†There were a total of 35 hit and run collisions during the study period; of these, 28 drivers were cited.

vehicles at injury sites were also more likely to exceed those limits. Half of the injury sites with posted speed limits showed average vehicular speeds that exceeded the posted limit compared with one third at non-injury comparison sites. Incident sites were four times more likely to be near a convenience store, gas station, and/or fast food restaurant located in the same block, than control sites.

When odds ratios are mutually adjusted, only speed and non-residential neighborhood show significantly increased odds ratios. Case sites were 4.92 times more likely to have average vehicle speeds exceeding the posted limit, and case sites were 3.72 times more likely to be near convenience stores, gas stations, or fast food restaurants. After adjustment, traffic signs and signals, crosswalks, parking, and visual obstructions were not significantly related to whether or not the site was one at which an injury had occurred during the study period.

\section{HOSPITAL VISITS}

Over $50 \%$ of the non-fatally injured children treated at the four participating hospitals were admitted for observation or treatment. The average length of stay for these children was 8.9 days, with a range of one to 150 days and a mode of one day.

The single most common $(67 \%)$ type of injury sustained by children in both pedestrian and bicycle related collisions was head injury. Among the $70 \%$ of the cases for whom Glasgow coma scores were recorded, $86 \%$ had a score between 13 and 15 indicating that the brain injury was not considered severe or moderate. AIS, ${ }^{11}$ injury severity scale (ISS), ${ }^{11}$ and injury impairment scale (IIS) ${ }^{15}$ scores were calculated using ICD9 diagnosis codes for non-fatal cases. The ISS reflects a composite severity constructed from the severity scores assigned to the case's three most severely injury body regions. The IIS is a closely related system of scoring which rates each injury on an integer scale denoting the injury's anticipated long term consequences.

Fifty two per cent of pedestrians and $34 \%$ of bicyclists had injury diagnosis codes that were used to generate AIS codes. Children who had diagnostic information that could be converted to AIS scores were more likely to have been admitted to the hospital than those who had no injury coding possible $(75 \%$ v 28\% among pedestrians; $74 \%$ v 32\% among bicyclists), and their hospital charges were higher $(\$ 15599 v$ $\$ 2509$, pedestrians; $\$ 11547 v \$ 7370$, bicyclists, 1990 US dollars). Hence, the pedestrians and bicyclists who had ICD9 codes assigned to them tended to be more severely injured. Because some ICD 9 codes can be interpreted as more than one possible AIS score, we developed upper and lower bounds for AIS scores, bounds that were extended to the calculation of the ISS and IIS scores. The mean ISS score ranged from 6.4 to 14.2 depending on use of the lower or upper AIS value. IIS scores also indicated no or limited impairment for the majority of children. Ten children had IIS scores which would indicate marked impairment of most useful function; however, for all but one of these children, the lower scores indicated no impairment.

\section{Discussion}

This study was originally designed as a rapid community surveillance effort, but was subsequently expanded to include environmental components. Several cautions are necessary when interpreting the findings. US census population estimates for the City of Long Beach provided the denominators on which rates were based, but the census may underestimate some minority and immigrant community members. Hence, using census counts of the population may serve to overestimate risk rates associated with minority status. Using census estimates to calculate rates is also

Table 5 Crude and adjusted odds ratio (OR) and $95 \%$ confidence interval (CI) for selected environmental risk factors for pedestrian/bicyclist injuries, Long Beach, $C A, 1988-90$

\begin{tabular}{|c|c|c|c|c|}
\hline Block characteristic & $\begin{array}{l}\text { No of } \\
\text { case sites }\end{array}$ & $\begin{array}{l}\text { No of } \\
\text { control sites }\end{array}$ & Crude OR $(95 \% \mathrm{CI})$ & Adjusted $\mathrm{OR}(95 \% \mathrm{CI})$ \\
\hline $\begin{array}{l}\text { Traffic signal present } \\
\text { Stop sign present } \\
\text { Speed limit posted } \\
\text { Average speed exceeded posted limit } \\
\text { Sidewalk present } \\
\text { Crosswalk present } \\
\text { Pedestrian crossing sign } \\
\text { Vehicles parked along road } \\
\text { Visual obscurement due to parked vehicles } \\
\text { Visual obscurement due to vegetation } \\
\text { Convenience store, gas station, or fast food } \\
\text { restaurant }\end{array}$ & $\begin{array}{r}36 \\
44 \\
40 \\
20 \\
102 \\
52 \\
13 \\
96 \\
68 \\
18 \\
45\end{array}$ & $\begin{array}{r}15 \\
67 \\
18 \\
6 \\
103 \\
23 \\
8 \\
106 \\
76 \\
20 \\
17\end{array}$ & $\begin{array}{l}3.07(1.49 \text { to } 6.38) \\
0.43(0.24 \text { to } 0.76) \\
2.91(1.47 \text { to } 5.79) \\
2.00(0.55 \text { to } 7.51) \\
0.94(0.59 \text { to } 1.50) \\
3.37(1.79 \text { to } 6.37) \\
1.71(0.63 \text { to } 4.74) \\
0.30(0.09 \text { to } 0.93) \\
0.73(0.40 \text { to } 1.31) \\
0.88(0.41 \text { to } 1.87) \\
4.31(2.25 \text { to } 8.33)\end{array}$ & $\begin{array}{l}0.43(0.12 \text { to } 1.63) \\
0.64(0.31 \text { to } 1.30) \\
0.94(0.42 \text { to } 2.08) \\
4.92(1.71 \text { to } 14.15) \\
1.58(0.36 \text { to } 6.82) \\
2.54(0.87 \text { to } 7.37) \\
0.88(0.26 \text { to } 3.03) \\
0.41(0.10 \text { to } 1.67) \\
0.82(0.40 \text { to } 1.67) \\
1.54(0.69 \text { to } 3.45) \\
3.72(1.76 \text { to } 7.89)\end{array}$ \\
\hline
\end{tabular}


potentially problematic because they are an ecologic measure of exposure. Better exposure estimates for pedestrian injuries would incorporate time spent outside, time spent near or crossing streets, and so on. Exposure for bicyclist injuries should reflect person-time spent actually riding bicycles. In the absence of such precise estimates of exposure, we have used census population estimates and acknowledge that their use assumes that each child is at equal risk.

Not all case sites were matched to a control site for study; this was due both to design considerations (not repeating the same site at which more than one injury had occurred) and to budgetary constraints. Up to as much as one year elapsed between the injury incident and the corresponding environmental assessments. We determined that no major roadway changes, speed limits or signage occurred during this time period (personal communication, Long Beach City Traffic Engineer's Office), however, minor modifications to visability and roadway surface repairs may have occurred during this period. Further, environmental assessments were not always conducted at the same time of day as the injury incident. However, case and control site observations were conducted at similar times of day so that case-control comparisons are valid, although not necessarily generalizable to individual incident locations. Although we were unable to conduct environmental assessments during dusk or night hours (for safety reasons), almost $95 \%$ of the incidents occurred during daylight hours and therefore differential lighting conditions probably do not present a bias. However, the present study allowed no control over traffic volumes or traffic behavior, which may vary considerably during the day, especially on streets used by commuters. Differences in time of evaluation between the incident and the observation of the incident location may lead to some bias in the determination of traffic patterns and vehicle speed.

Based on these findings, the incidence rates and the variations according to age, gender, and ethnicity are comparable with those determined by other investigators. One national estimate, based on police reported pedestrian injuries in six states, was $76 \cdot 9 / 100000$ for boys and girls combined, 14 years and younger. ${ }^{6}$ If our cases had been determined solely on the basis of police reports, we would have had a pedestrian incidence rate of 108.5/100000. National rates were highest among boys aged $5-9$ years; the police based estimate was $142 \cdot 4$ whereas we found an incidence rate of 211 for 5-9 year old boys. The Massachusetts Statewide Childhood Injury Prevention Program reported a pedestrian injury rate of 160 per 100000 for $0-12$ year olds and 13-19 year olds, ${ }^{16}$ based on hospital (emergency department and admission) records and coroner reports. The Northeast Ohio Trauma Study reported a non-fatal injury incidence rate of $198 / 100000$ for children 5-9 years. ${ }^{17}$

The discrepancy between injury rates for police and hospital reports has important implications for injury surveillance. Comprehen- sive population based surveillance must combine case ascertainment from many reporting sources because no single source can be expected to identify all injured pedestrians. Police do not respond to all traffic incidents and, even if they did, not all children are hit in 'traffic' situations; a distinct minority are struck on private property under conditions that may or may not generate a police report. Occasionally an injured child is transported to medical care by private vehicle before police arrive at the scene. Similarly, cases identified through hospital records also suffer from selection bias. Children who are not medically treated, or who are treated by a primary care physician in a non-hospital setting, are seldom identified. In this study, however, we found hospital records for every police reported incident. The rates reported here are based on injuries serious enough to require emergency treatment and should not be interpreted to include all severities of childhood pedestrian injuries.

Non-white ethnicity is also an established risk marker for pedestrian injuries. ${ }^{39}{ }^{18}$ In Long Beach, we found all non-white groups to be at increased risk compared with whites, and Asians to have the highest risk of any ethnic groups. This finding is consistent with the experience of the health care professionals who initially suggested this investigation. Although non-white ethnicity appears to be a marker for increased risk of injury, the mechanisms through which this operates need to be explored more fully. This may relate to recent immigration status to the US, which in turn may indicate unfamiliarity with the English language and urban US traffic patterns. Child rearing practices that were developed in regions of the world with drastically different traffic volumes and patterns than those found in the Los Angeles area may have shortcomings in the face of more hazardous traffic environments. At the same time, recent immigration status may be associated with a reduced social support network. If immigrant status is found to be one mechanism through which ethnicity operates as a risk marker, then preventive strategies logically should include interventions aimed at immigrants at the time of arrival into this country.

Low socioeconomic status may be associated with conditions in the physical and social environments that have direct bearing on pedestrian exposure..$^{19}$ In the physical environment low socioeconomic status may be associated with neighborhoods where residential units are in close proximity to areas of heavy traffic flow, neighborhoods with more crowding, activity, or distraction, or residential areas with scarce or inadequate recreational areas. In the social environment, low socioeconomic status may be related to chaotic circumstances, attitudes of reduced power and control, and child caregivers whose time and attention are taxed in other ways, compromising supervisorial ability. Each of these hypotheses deserves proper investigation.

In the present study, only six out of $219\left(4^{\circ}{ }_{0}\right)$ children were injured on private property 
(driveways and parking lots), and only one out of $19(5 \%)$ fatalities occurred on private property. This is in contrast to other recent US reports, which have found greater proportions of non-fatal injuries occurring on private property, particularly driveways. ${ }^{20}$ However, Rivara found that the majority of fatal injuries to children occur on busy streets and arterials. ${ }^{6}$ Children struck in driveways are generally recognized as an etiologically distinct group compared with children hit on public roadways. The six children injured on private property in Long Beach tended to be younger than those struck on roadways. The absence of driveway incidents could well stem from the fact that many sections of Long Beach have relatively few driveways (for example, apartment complexes with street parking only). We also found that most children were struck in close proximity to their homes. Mueller et al reported a similar finding in their study of childhood pedestrian-motor vehicle collisions in King County, Washington during 1985-6. Among children 14 and younger who were injured severely enough to be hospitalized or die, $34 \%$ of injuries (23 out of 67 known locations) occurred in front of or within 150 feet of the child's residence, and all but nine $(87 \%)$ occurred within one mile of the child's home. ${ }^{7}$ In Cape Town, South Africa, almost nine in every 10 child pedestrian injuries occurred in front of the child's home or in the immediate neighborhood. ${ }^{21}$

We found the single most common pedestrian exposure to be midblock dart-outs; that is, children who run out into the street, often from between parked cars. ${ }^{22}$ Further efforts are needed to explore whether the dart-out was a function of the child's play in or near the street, the role of motivation - what the child was running to or from - and the absence of proper supervision.

\section{IMPLICATIONS FOR PREVENTION}

Childhood injuries due to pedestrian and bicyclist collisions remain a serious pediatric injury problem. Our findings suggest three possible routes for the prevention of these injuries and fatalities: education, law enforcement, or environmental modification.

Educating children and their parents about traffic safety and safe play to produce changes in behavior and action is a complicated, costly, and long term approach. Although, in theory, a multidisciplinary, culturally sensitive (including language appropriate) educational program is attractive, few evaluations of educational programs have been encouraging. Potentially successful educational programs must address children's behaviour and the environments in which they are likely to be struck, including aspects of the social environment, such as supervision. An effective educational campaign should aim not only at the child and the parents, but also at drivers and the larger community by involving schools, hospitals, community groups, and the media. The goal of educational programs is to change behavior to reduce injury, as well as to heighten awareness to create a climate in which circumstances conducive to pedestrians are recognized and mechanisms to separate children from traffic are promoted.

Enforcement as an injury prevention strategy centers largely on control of motor vehicle speeds and obedience to traffic signs and signals. For enforcement to have long term effects this strategy must be implemented consistently over a long period. In our study, 13\% of the incidents involved a hit-and-run by a motorist. Increasing police attention to hitand-run incidents involving children may serve, in the long term, to reduce this type of injury event.

Environmental strategies involve physically separating the pedestrian from vehicle traffic such as through the creation of separate pathways or physical barriers, and traffic pattern modifications like calming and sequence control. These changes may improve the visibility of relevant safety factors (for example, signs, crosswalks) for both drivers and pedestrians. Since they do not require changes in behavior, the environmental strategy has the advantage of being passive to the pedestrian. On the other hand, the necessary modifications can be expensive to implement.

Based on the results of this study, several possible environmental changes may be considered. The combination of highly visible international crosswalk designations with speed control devices, such as ceramic roadway markers that jolt the driver's attention, could increase safety in and around crosswalks. One way roads may increase driver ability to constantly survey the environment. Diagonal, rather than parallel, parking could increase the buffer zone between pedestrian movement and traffic, and may, therefore, prevent dart-outs. Introducing fenced-in play areas for children may also be effective in reducing dart-out injuries, especially in those areas where children presently have few play area choices. These strategies are intuitively attractive but need to be rigorously evaluated for effectiveness as well.

We wish to thank the staffs of the City of Long Beach hospitals and agencies that provided data for this study. In particular, we thank Sergeant Wendall Armstrong of the Long Beach Police Department, and members of the Pedestrian Safety Task Force for their support. Invaluable assistance was provided by Judy Cohen, Mary Jane Foster, Ginger Gruzinski, and Pat Kinder a St Mary's Medical Center, and Patty Conn and Elizabeth Raganold at Long Beach Memorial Hospital. We thank Richard Raganold at Long Beach Memorial Hospital. We thank Richard Backus and Peter Corpuz of the Long Beach Department of Public Works for traffic related information and advice. Finally, we wish to thank Linda Lange, MPH, Soumitra Sarkar, MD MPH, and Preet Dhillon for their work in data collection, coding, and analysis.

This study was supported by the Southern California Injury Prevention Research Center (Centers for Disease Control and Prevention R49/CCR903622).

1 Baker SP, O'Neill B, Ginsburg MJ, Li G. The injury fact book. New York: Oxford University Press, 1992.

2 National Highway Traffic Safety Administration. Traffic safety facts 1993. Washington, DC: US Department of Transportation, 1994

3 Rivara FP, Barber M. Demographic analysis of childhood pedestrian injuries. Pediatrics 1985; 76: 375-81.

4 Neresian WS, Petit MR, Shaper R, et al. Childhood death and poverty: a study of all childhood deaths in Maine, and poverty: a study of all childhood 1976 to 1980 . Pediatrics $1985 ; 75$ : 41-50. 
5 Pless IB, Verreault R, Arsenault R, et al. The epidemiology of road accidents in childhood. Am $¥$ Public Health 1987; 77: 358-60.

6 Rivara FP. Child pedestrian injuries in the United States: current status of the problem, potential interventions, and
future research needs. Am $\mathcal{F}$ Dis Child 1990; 144: 692-6.

7 Mueller BA, Rivara FP, Lii SM, Weiss NS. Environmental factors and the risk for childhood pedestrian-motor vehicle collision occurance. Am $\mathcal{F}$ Epidemiol 1990; 132: vehicle
$550-60$.

8 Joly MF, Foggin PM, Pless B. Geographical and socioecological variations of traffic accidents among children. Soc Sci Med 1991; 7: 765-9.

9 King W, Palmisano P. Racial differences in childhood hospitalized pedestrian injuries. Pediatr Emerg Care 1992; 8: $221-4$

10 Friede AM, Azzara CV, Gallagher SS, Guyer B. The epidemiology of injuries to bicycle riders. Pediatr Clin North Am 1985; 32: 141-51.

11 Association for the Advancement of Automotive Medicine. The abbreviated injury scale. Des Plaines, IL: AAAM, 1990.

12 Stevenson MR, Jamrozik KD, Spittle J. A case-control study of traffic risk factors and child pedestrian injury. Int $\Im$ Epidemiol 1995; 24: 957-64.

13 Agran PF, Winn DG, Anderson CL, Tron C, Del Valle CP. The role of the physical and traffic environment in child pedestrian injuries. Pediatrics (in press)
14 SAS Institute Inc. $S A S$ version 6. Cary, NC: SAS Institute Inc, 1989.

15 Association for the Advancement of Automotive Medicine. Injury impairment scale 1994. Des Plaines, IL: AAAM, 1994.

16 Gallagher SS, Finison K, Guyer B, Goodenough S. The incidence of injuries among 87,000 Massachusetts children and adolescents: results of the 1980-81 statewide childhood injury prevention program surveillance childhood injury prevention program sur

17 Malek M, Guyer B, Leschohier I. The epidemiology and prevention of child pedestrian injuries. Accid Anal Prev 1990; 22: 301-13.

18 Roberts I, Norton R. Child pedestrian injury 1978-87. NZ Med f 1992; 105: 51-2.

19 Roberts I, Marshall R, Norton R, Borman B. An area analysis of child injury morbidity in Auckland. $\mathcal{f}$ Pediat Child Health 1992; 28: 438-41.

20 Agran P, Winn D, Anderson C. Differences in child pedestrian injury events by location. Pediatrics 1994; 93: 284-8.

21 Bass DH, Albertyn R, Melis J. Road traffic collisions involving children as pedestrians. Provisional results of a hospital-based study. $S$ Afr Med f 1992; 82: 268-70.

22 Schofer JL, Christoffel KK, Donovan M, Lavigne JV, Tan RR, Wills KE. Child pedestrian injury taxonomy based on visibility and action. Accid Anal Prev 1995; 27: on visibilit

\section{Editorial Board Member: brief biography}

CAROL RUNYAN

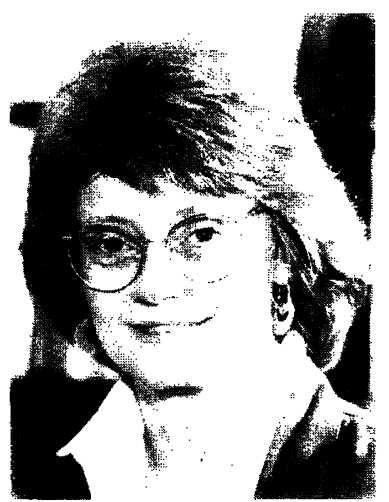

Dr Carol Runyan is Director of the University of North Carolina (UNC) Injury Prevention Research Center and a faculty member in the UNC School of Public Health (Department of Health Behavior and Health Education). She received her $\mathrm{PhD}$ in 1983 at UNC in health behavior, with emphasis on injury epidemiology and public policy. She then completed a postdoctoral fellowship in 1986 in injury epidemiology at Johns Hopkins University. Her research has addressed child and adolescent injury, particularly exposures in child care and in occupational settings; residential fires; and violence against women. She is currently conducting research on workplace violence, female homicide and suicide, women's selection of self protection strategies, and teen work hazards. Dr Runyan has an active teaching role working with public health graduate students conducting injury research on many topics and is developing a distance learning course for practicing professionals in local settings. 